\title{
Capsule Endoscopy Detection of Ileal Mucosa Alterations due to Cow Milk Malabsorption in a Celiac Patient
}

\author{
Raffaele Pezzilli*, Giuseppina Liguori and Carlo Calabrese \\ Department of Digestive Diseases and Internal Medicine, Sant'Orsola-Malpighi Hospital, Alma Mater Studiorum-University of Bologna, Bologna, Italy
}

\begin{abstract}
We report a case of a 77-year-old man suffering from celiac disease admitted as an outpatient to our clinic for the persistence of bloating and diarrhea without macroscopic steatorrhea, weight loss or an increase in circulating carbohydrate antigen 19-9. An esophagogastroduodenoscopy showed $H$. pylori negative antral gastritis and atrophy of the duodenal mucosa and the results of a colonoscopy were normal. Abdominal contrast-enhanced computed tomography did not show any parenchymal alteration of the liver and pancreas. The patient underwent a capsule endoscopy and the examination showed the presence of villous atrophy with microerosions at the level of the medial jejunum, in the ileum, and some areas of lymphangiectasia. A repeated capsule endoscopy after starting a lactosefree diet showed the normalization of the jejunum-ileum villous atrophy. At present, the patient is in good general health and continues a gluten- and cow milk-free diet. We should be aware that celiac patients may have lactose intolerance that cause malabsorption; the transient increase of CA 19-9 in celiac patients may be due to causes other than the presence of gastrointestinal cancer; the capsule endoscopy is useful in detecting ileal mucosa abnormalities which disappear after going on gluten- and cow milk-free diet.
\end{abstract}

Keywords: Celiac disease; Cow milk intolerance; Wireless capsule endoscopy; Outcome

\section{Introduction}

Lactose intolerance is a frequent cause of gastrointestinal symptoms worldwide, including bloating, flatulence and diarrhea, appearing after the ingestion of food products containing lactose [1]. The degree of discomfort depends primarily on the amount of lactose ingested as well as the sensitivity to lactose [2]. The association of cow milk intolerance in celiac disease patients has been reported [3] by means of histology and disaccharidase activities of duodenal mucosal biopsies. To this end, we report the case of lactose intolerance in a patient with celiac disease in whom the diagnosis of lactose intolerance was assessed by means of a lactose breath test, and ileal alterations were detected by using capsule endoscopy.

\section{Case Report}

We describe, after had he given informed consent, the case of 77-year-old man suffering from celiac disease which had been histologically diagnosed at the age of 68 years and who was on glutenfree diet. He was admitted as an outpatient to our clinic in September 2010 for the persistence of bloating and diarrhea without macroscopic steatorrhea, weight loss (about 4 kilos) and an increase in circulating carbohydrate antigen 19-9 (CA 19-9) levels (72 U/mL, upper reference limit $<37$ ) that were apparently not due to other medical problems.

The patient was compliant with the gluten-free diet as was also confirmed by his spouse. Blood examinations were unremarkable as was the total $\operatorname{IgE}(53 \mathrm{U} / \mathrm{L}$, upper reference value 100$)$, the serum IgA were $241 \mathrm{mg} / \mathrm{dL}$ (reference range 70-400) and the serum determination of both immunoglobulin A antibodies to deamidated gliadin peptides $(0.8 \mathrm{U} / \mathrm{mL}$, upper reference value: $25 \mathrm{AU} / \mathrm{mL})$ and to tissue transglutaminase $(0.5 \mathrm{U} / \mathrm{mL}$, upper reference value: $7 \mathrm{U} / \mathrm{mL})$. Fecal occult blood examination was also negative and fecal elastase 1 was within the normal limit. An esophagogastroduodenoscopy showed $H$. pylori negative antral gastritis and atrophy of the duodenal mucosa and the results of a colonoscopy were normal (biopsies showed a normal colonic mucosa). Abdominal contrast-enhanced computed tomography did not show any parenchymal alteration of the liver and pancreas. To better investigate the etiology of the diarrhea, the patient underwent an $\mathrm{H}_{2}$ breath test with lactose. After a baseline breath sample was measured, $25 \mathrm{~g}$ of oral lactose was administered and breath samples were taken every 30 minutes; the presence of hydrogen in parts per million (ppm) was determined by using a QuinTron MicroLyzer (Milwaukee, WI); this examination revealed milk-induced malabsorption because there was a rise in hydrogen excretion of more than $20 \mathrm{ppm}$ above the baseline (Figure 1).

In order to evaluate the extension of small bowel lesions, the patient underwent a capsule endoscopy (Given Imaging, Yoqneam, Israel). This examination showed the presence of villous atrophy with microerosions at the level of the medial jejunum and in the ileum, and some areas of lymphangiectasia (Figure 2).

After starting a lactose-free diet, the gastrointestinal symptoms rapidly disappeared; CA $19-9$ returned to normal values $(27 \mathrm{U} / \mathrm{mL})$ and the patient regained his normal body weight. A capsule endoscopy was carried out again after six months; this examination showed the normalization of the previously described jejunum-ileum villous atrophy (Figure 3). The six months post milk free diet lactose breath test was also normal (Figure 4). At present, the patient is in good general health and continues a gluten- and cow milk-free diet.

\section{Discussion}

This case was of particular interest for the following reasons:

*Corresponding author: Raffaele Pezzilli, Department of Digestive Diseases and Internal Medicine, Sant'Orsola-Malpighi Hospital, Bologna, Italy, Tel: +39-0516364148; Fax: +39-0516364148; E-mail: raffaele.pezzilli@aosp.bo.it

Received November 09, 2012; Accepted December 12, 2012; Published December 18, 2012

Citation: Pezzilli R, Liguori G, Calabrese C (2012) Capsule Endoscopy Detection of lleal Mucosa Alterations due to Cow Milk Malabsorption in a Celiac Patient. J Aller Ther 3:125. doi:10.4172/2155-6121.1000125

Copyright: ( 2012 Pezzilli R, et al. This is an open-access article distributed under the terms of the Creative Commons Attribution License, which permits unrestricted use, distribution, and reproduction in any medium, provided the original author and source are credited. 


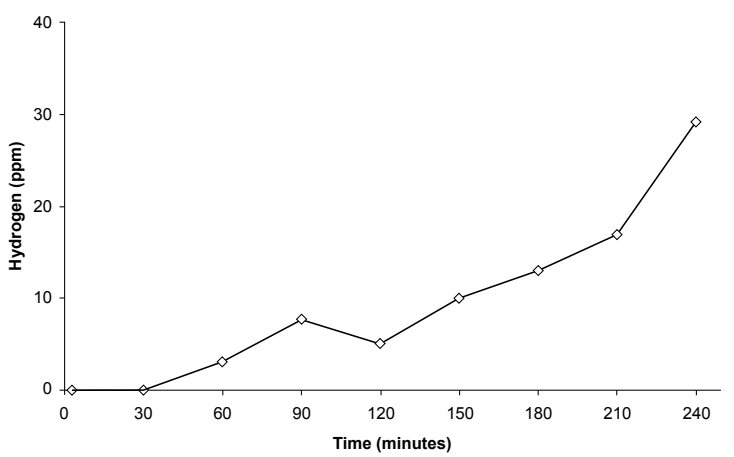

Figure 1: Lactose breath test. After a baseline breath sample was measured, $25 \mathrm{~g}$ of oral lactose was administered, and breath samples were taken every 30 minutes and the presence of hydrogen in parts per million (ppm) was determined by gas chromatography. Milk-induced malabsorption was diagnosed as demonstrated by the rise in hydrogen excretion of more than 20 ppm above baseline.

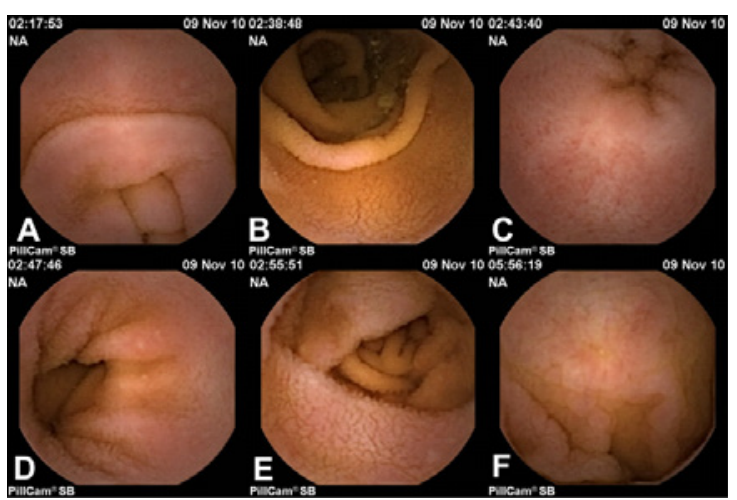

Panels A-D: jejunum with villous atrophy and microerosions (D) Panels E,F: ileum with villous atrophy

Figure 2: Capsule endoscopy at diagnosis.

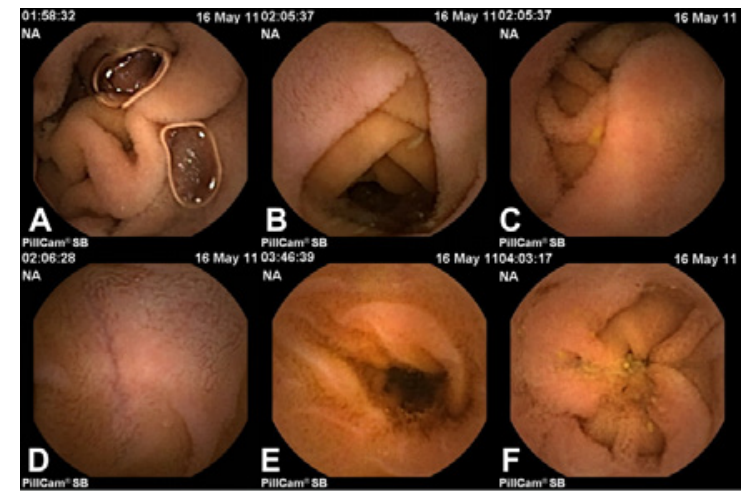

Panels A-D: normal jejunum

Panels E,F: normal ileum

Figure 3: Capsule endoscopy after 6 months

first, the appearance of gastrointestinal symptoms, such as bloating, diarrhea and weight loss, due to the appearance of lactose intolerance [4]; second, the transient increase of CA 19-9 in celiac patients which was due to causes other than the presence of gastrointestinal cancer, which usually indicates in the general population [5], and third, capsule endoscopy was useful in detecting ileal mucosa abnormalities which disappear after going on a gluten- and cow milk-free diet.
Nonresponsive celiac disease is a common problem affecting $7-30 \%$ of celiac patients. Gluten exposure was the most common cause in one-third of nonresponsive celiac disease, but other causes can be recognized, such as irritable bowel syndrome, refractory celiac disease, microscopic colitis and lactose intolerance in about $8 \%$ of the cases [6]. It has also been reported that disaccharidase activity analysis offers additional information for evaluating the severity of mucosal villous atrophy especially during follow-up in patients with celiac disease; in fact, decreased activity of maltase or sucrase in these patients may be responsible for mucosal villous atrophy [3]. In addition, no patient with normal disaccharidase activity had severe villous atrophy [3]. Why cow milk intolerance can appear during the course of celiac disease is still under debate. Some authors have claimed that there are gluten-free peptides present in cow milk [7]; others have found that no significant amount of high molecular weight glutenin proteins can be detected in bovine milk, and the intolerance of celiac disease patients to bovine milk is not due to the presence of T-cell stimulatory epitopes of gluten [8]. The fact that the immunoglobulin A antibodies to deamidated gliadin peptides and the tissue transglutaminase antibodies were normal in our patient could support this latter hypothesis. Finally, because the $\mathrm{H}_{2}$ breath test with lactose after eliminating the cow-milk from the diet was normal, the gluten proteins contamination in the milk lead to the patient's symptoms and findings.

Another interesting aspect of this case is the transient increase of serum CA 19-9; the levels of this marker returned to normal after he went on a cow milk-free diet. CA 19-9 is synthesized by normal human pancreatic and biliary ductular cells as well as by gastric, colonic, endometrial, and salivary epithelia [9]. Persistent high serum levels of this cancer marker have also been reported in serum CA 19-9 with no evidence of malignant disease [5] as well as in patients with nonmalignant diffuse lung diseases, such as idiopathic pulmonary fibrosis, bronchiectasis, cystic fibrosis [10] and diabetes mellitus [11]. It has been shown that increased CA 19-9 serum levels are present in patients with hypothyroidism, and the gradual improvement of the thyroid function resulted in the resolution of the elevated CA 19-9 levels [12]. Thus, it is possible that, as in our patient, the serum levels of CA19-9 normalized after the disappearance of the ileal lesions.

Finally, current guidelines recommend that patients with refractory celiac disease undergo capsule endoscopy [13], even if the role of this technique in celiac patients is complementary. When careful history and serological markers rule out noncompliance with a gluten-free diet, capsule endoscopy is indicated for detecting complications, such as cancer, ulcerative jejunitis or ileitis and other associated conditions such as collagenous sprue [13]. Our report suggests the use of capsule

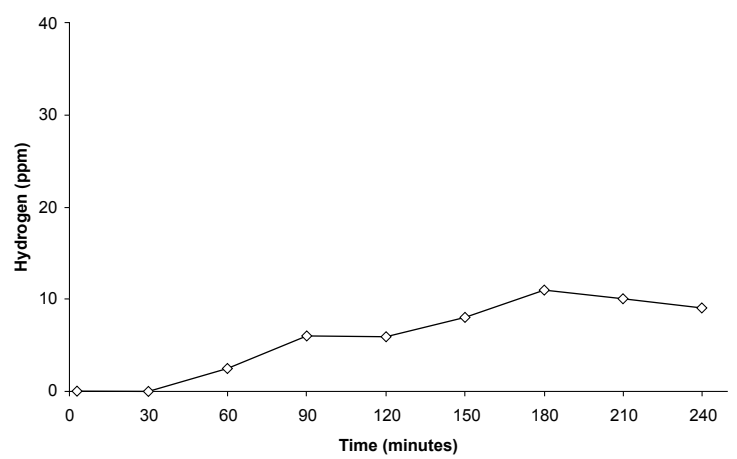

Figure 4: Lactose breath test after six months from the elimination of the cow-milk from the diet. The test demonstrated a normal hydrogen excretion. 
Citation: Pezzilli R, Liguori G, Calabrese C (2012) Capsule Endoscopy Detection of lleal Mucosa Alterations due to Cow Milk Malabsorption in a Celiac Patient. J Aller Ther 3:125. doi:10.4172/2155-6121.1000125

Page 3 of 3

endoscopy in this diagnostic approach can be utilized in celiac patients with symptomatic lactose intolerance for the detection of ileal mucosa abnormalities and their subsequent disappearance after starting cow milk-free diet.

\section{References}

1. Law D, Conklin J, Pimentel M (2010) Lactose intolerance and the role of the lactose breath test. Am J Gastroenterol 105: 1726-1728.

2. Gudmand-Høyer E (1994) The clinical significance of disaccharide maldigestion. Am J Clin Nutr 59: 735S-741S.

3. Nieminen U, Kahri A, Savilahti E, Färkkilä MA (2001) Duodenal disaccharidase activities in the follow-up of villous atrophy in coeliac disease. Scand $J$ Gastroenterol 36: 507-510.

4. Mozer-Glassberg $\mathrm{Y}$, Zevit N, Rosenbach $\mathrm{Y}$, Hartman $\mathrm{C}$, Morgenstern S, et al. (2011) Follow-up of children with celiac disease-lost in translation? Digestion 83: 283-287.

5. Ventrucci M, Pozzato P, Cipolla A, Uomo G (2009) Persistent elevation of serum CA 19-9 with no evidence of malignant disease. Dig Liver Dis 41: 357-363.

6. Leffler DA, Dennis M, Hyett B, Kelly E, Schuppan D, et al. (2007) Etiologies and predictors of diagnosis in nonresponsive celiac disease. Clin Gastroentero Hepatol 5: 445-450.
7. Cabrera-Chávez F, de la Barca AM (2009) Bovine milk intolerance in celiac disease is related to IgA reactivity to alpha- and beta-caseins. Nutrition 25 715-716.

8. Dekking L, Koning F, Hosek D, Ondrak TD, Taylor SL, et al. (2009) Intolerance of celiac disease patients to bovine milk is not due to the presence of T-cell stimulatory epitopes of gluten. Nutrition 25: 122-123.

9. Kim JE, Lee KT, Lee JK, Paik SW, Rhee JC, et al. (2004) Clinical usefulness of carbohydrate antigen 19-9 as a screening test for pancreatic cancer in an asymptomatic population. J Gastroenterol Hepatol 19: 182-186.

10. Kodama T, Satoh H, Ishikawa H, Ohtsuka M (2007) Serum levels of CA19-9 in patients with nonmalignant respiratory diseases. J Clin Lab Anal 21: 103-106.

11. Petit JM, Vaillant G, Olsson NO, Guignier F, Collignon S, et al. (1994) Elevated serum CA19-9 levels in poorly controlled diabetic patients. Relationship with Lewis blood group. Gastroenterol Clin Biol 18: 17-20.

12. Tekin O (2002) Hypothyroidism-related CA 19-9 elevation. Mayo Clin Proc 77 398.

13. Ladas SD, Triantafyllou K, Spada C, Riccioni ME, Rey JF, et al. (2010) European Society of Gastrointestinal Endoscopy (ESGE): Recommendations (2009) on clinical use of video capsule endoscopy to investigate small-bowel, esophageal and colonic diseases. Endoscopy 42: 220-227. 